\title{
Photosynthesis of Scenedesmus obliquus in outdoor open thin-layer cascade system in high and low $\mathrm{CO}_{2}$ in Belgium
}

\author{
de Marchin Thomas $^{\mathrm{a}}$, Erpicum Michel ${ }^{\mathrm{b}}$, and Franck Fabrice * a

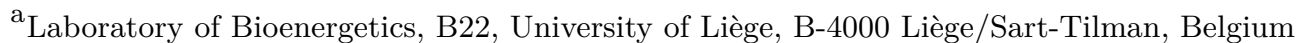 \\ ${ }^{\mathrm{b}}$ Laboratory of climatology and topoclimatology, B11, University of Liège, B-4000 Liège/Sart-Tilman, Belgium
}

Accepted for publication in Journal of biotechnology, June 25, 2015

The original publication is available at http://www.sciencedirect.com/science/article/pii/S0168165615300511

\begin{abstract}
Two outdoor open thin-layer cascade systems operated as batch cultures with the alga Scenedesmus obliquus were used to compare the productivity and photosynthetic acclimations in control and $\mathrm{CO}_{2}$ supplemented cultures in relation with the outdoor light irradiance. We found that the culture productivity was limited by $\mathrm{CO}_{2}$ availability. In the $\mathrm{CO}_{2}$ supplemented culture, we obtained a productivity of up to $24 \mathrm{~g} \mathrm{dw} \cdot \mathrm{m}^{-2}$. day ${ }^{-1}$ and found a photosynthetic efficiency (value based on the PAR solar radiation energy) of up to $5 \%$. In the $\mathrm{CO}_{2}$ limited culture, we obtained a productivity of up to $10 \mathrm{~g} \mathrm{dw} \cdot \mathrm{m}^{-2}$.day ${ }^{-1}$ while the photosynthetic efficiency was up to $3.3 \%$ and decreased to $2.1 \%$ when the integrated daily PAR increased. Fluorescence and oxygen evolution measurements showed that ETR and oxygen evolution light saturation curves, as well as lightdependent $\mathrm{O}_{2}$ uptake were similar in algal samples from both cultures when the $\mathrm{CO}_{2}$ limitation was removed. In contrast, we found that $\mathrm{CO}_{2}$ limitation conducted to a decreased PSII photochemical efficiency and an increased light-induced heat-dissipation in the control culture compared to the $\mathrm{CO}_{2}$ supplemented culture. These features are in line with a lower light use efficiency and may therefore contribute to the lower productivity observed in absence of $\mathrm{CO}_{2}$ supplementation in outdoor mass cultures of Scenedesmus obliquus.
\end{abstract}

\section{Introduction}

Over the last decades, microalgae have been increasingly studied because of their potential applications in the industry. Because of their great biodiversity, microalgae can produce a lot of valuable compounds for biofuels, food and feed, pharmaceutical and cosmetic industry. Despite a growing interest in microalgae mass cultures, the majority of studies on microalgae have been carried out at the laboratory scale and only few studies have addressed the question of photosynthetic acclimations in mass cultures.

Different mass culture systems are used in the world to produce microalgae biomass. Although some industry use closed tubular photobioreactors, most of microalgae biomass production units rely on horizontal open raceways systems (Zittelli et al., 2013). The advantage of raceways are a relatively low building cost as well as a simple design

\footnotetext{
${ }^{*}$ Corresponding author : F.Franck@ulg.ac.be
}

permitting a rapid development of the installation. The culture thickness of these systems is usually high (15-30 $\mathrm{cm}$ ), implying a low biomass density because of the reduced penetration of light in the suspension. Another drawback of these systems is the relatively poor mixing of the culture, which do not permit an efficient $\mathrm{CO}_{2}$ and $\mathrm{O}_{2}$ exchange with the atmosphere.

In this study, we used a thin-layer culture system similar to the one designed by Dr. Ivan Šetlík in the 1960s (Šetlík et al., 1970). This system is characterised by an inclined surface exposed to sunlight in which the algal suspension flows by gravity (fig 1 ). At the end of the inclined surface, the suspension falls in a tank and is then pumped to the upper part of the inclined surface. Transverse laths are placed on the inclined surface in order to increase the mixing of the suspension, to ensure good gas exchange with the atmosphere and to favour fast light-dark cycle. The tank serves as a buffer to cushion the volume changes due to high evaporation during hot days or to heavy rainfalls. The productivity, the $\mathrm{CO}_{2} / \mathrm{O}_{2}$ exchange properties and the different variants of this system have been well characterised in the past using Chlorella and Scenedesmus species (Kajan et al., 1994; Grobbelaar et al., 1995; Doucha and Lívanský, 1995; Lívanský and Doucha, 1996; Doucha and Livansky, 1999; Livansky, 2000; Doucha et al., 2005; Doucha and Lívanský, 2006; Doucha and Lívanský, 2009; Masojídek et al., 2011; Jerez et al., 2014). This system is currently used in a modified version for commercial production of Spirulina by the Biorigin farm in Ecuador.

Chlorophyll fluorescence has become one of the most common technique used to assess the photochemistry of photosynthetic organisms due to its non-invasiveness, sensitivity and to the wide availability of measuring instruments (Masojídek et al., 2010). Chlorophyll fluorescence reflects the performance of PSII and is thus influenced by processes occurring downstream of PSII. One of the most used chlorophyll fluorescence approach is the saturation-pulse (PAM) method. With this method, fluorescence can be recorded continuously without being affected by ambient light and photochemical quenching and non-photochemical quenching can be easily separated (for a review, see Baker, 2008). Several parameters have been developed to account for the photosynthetic performances of sample. Maximal photochemical efficiency of PSII $\left(\mathrm{F}_{\mathrm{V}} / \mathrm{F}_{\mathrm{M}}\right)$ is a parameter characterizing the proportion of absorbed light quanta which can be used by PSII to drive photosynthesis. The optimal value of this parameter is about $0.7-0.8$, meaning 

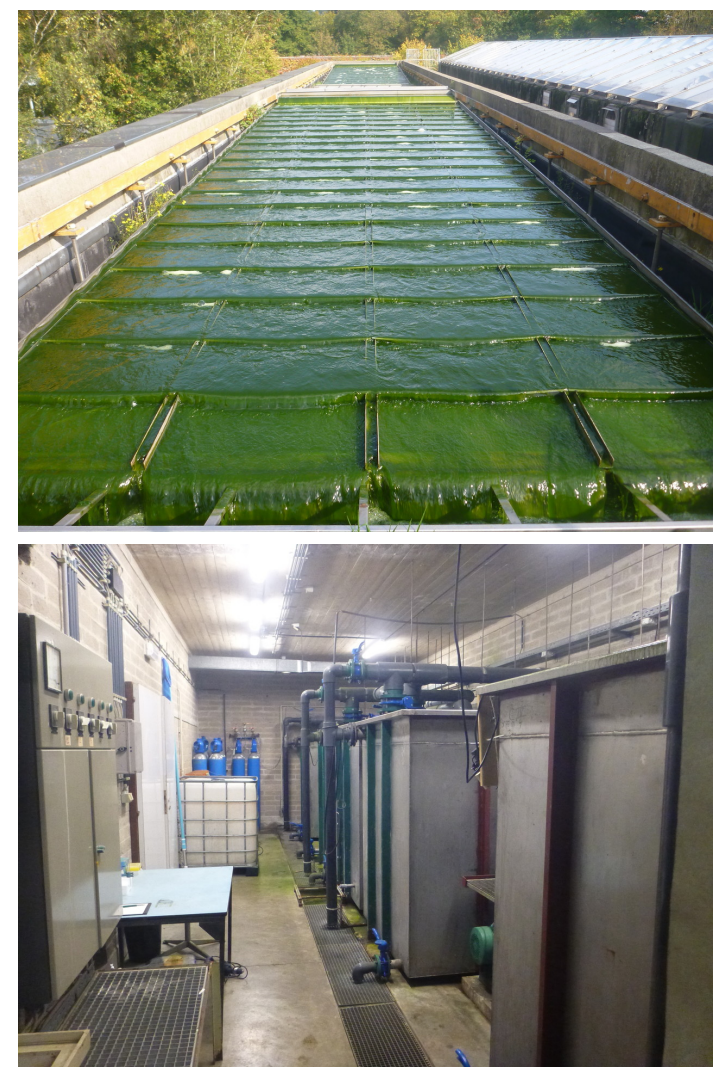
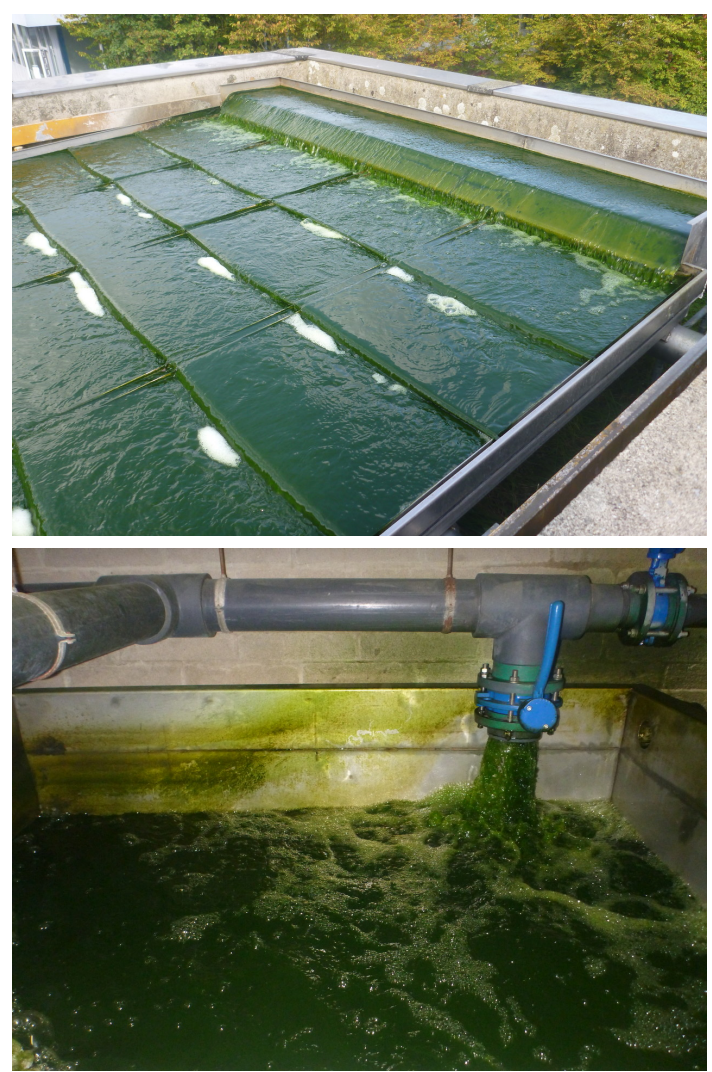

Figure 1: Top-left: light exposed part of the thin-layer cascade system on the roof. Top-right: zoom on the overflow tank. Bottom-left: engine room located downstairs. Bottom-right: zoom on a tank.

that in optimal conditions, about 70 to $80 \%$ of the absorbed light quanta are used for photochemistry while the rest is wasted as heat and fluorescence. This parameter is determined after dark-adaptation in order to permit the relaxation of dissipation and photoprotective processes. Another useful parameter is the PSII operating photochemical efficiency ( $\Phi$ PSII) measured under actinic light, which is a measure of the actual photochemical capacity of PSII when photosynthesis is active. This means that any stress affecting a component of the photosynthetic apparatus will be reflected by a decreased $\Phi$ PSII. Finally, non-photochemical quenching (NPQ) is a third parameter which is often calculated to determine if photoprotective mechanisms are activated to deal with excessive absorbed light energy. NPQ is reflected as a general decrease of the fluorescence level and is composed of three components: energy-dependent quenching $q \mathrm{E}$, which reflects an increased heat dissipation in the antennas, state transition qT which reflects a dissociation of light-harvesting complexes from PSII and photoinhibition qI, which reflect photodamages to PSII. These different components have different relaxation times ranging from a few seconds $(\mathrm{qE})$ to several minutes ( $\mathrm{qT}$ and $\mathrm{qI}$ ).

In photoautotrophic atmospheric conditions, microalgae often have to deal with limited $\mathrm{CO}_{2}$ availability, which prevents an efficient photosynthesis and a rapid growth. $\mathrm{CO}_{2}$ limitation is usually associated with a reduced productivity, with the development of the carbon concentrating mechanism (Moroney et al., 2011) and with a reduced PSII antenna size (Berger et al., 2014). In labscale experiments, electron transfer to $\mathrm{O}_{2}$ (most probably Mehler-type) has also been found to be very effective in condition of reduced $\mathrm{CO}_{2}$ availability in Chlamydomonas reinhardtii (Sueltemeyer et al., 1986; Bassi et al., 2012) and in Scenedesmus (Radmer and Kok, 1976; Radmer and Ollinger, 1980; Flameling and Kromkamp, 1998). Among the studies on microalgae mass culture, as far as we know, none directly compared high $\mathrm{CO}_{2}\left(\mathrm{CO}_{2}\right.$ supplemented $)$ and low $\mathrm{CO}_{2}$ (non $\mathrm{CO}_{2}$ supplemented) conditions. The aim of this study was to use chlorophyll fluorescence to analyse the possible photosynthetic acclimations of the culture in response to $\mathrm{CO}_{2}$ availability in outdoor mass culture. For this, we performed two simultaneous microalgae cultures with or without $\mathrm{CO}_{2}$ addition. Experiments were realised with Scenedesmus obliquus, which is known to have a high growth rate and a strong cell wall making it resistant for cultivation in various cultivation systems.

\section{Material and methods}

Organism and culture medium The Scenedesmus obliquus 276.10 strain was used for cultivation (SAG culture collection). The medium was made of FloraGro and FloraMicro (GHE) diluted in tap water. FloraGro and FloraMicro were added in a ratio $1: 1000$ and $1: 1000$, respectively, for each $4 \mathrm{~kg}$ of biomass accumulated. $\mathrm{N}$ content of the cultures was regularly checked to ensure that it was available and assimilated. This was taken as a indicator for the absence of nutrient limitation. FloraMicro and FloraGro composition can be found in Tocquin et al. (2012). In one culture, $\mathrm{pH}$ of the medium was stabilized to a value close to 7.5 by injecting pure $\mathrm{CO}_{2}$ while in the other, $\mathrm{pH}$ was not stabilized. 
Outdoor culture system The two outdoor open culture systems used for cultivation are similar to the one designed by Dr. Ivan Šetlík in the 1960s (Šetlík et al., 1970). They consists of a $35 \mathrm{~m}^{2}$ inclined surface (inclination $2.5^{\circ}$ ) exposed to sunlight. The suspension flows on the surface due to the gravity before falling in a tank located downstairs. The suspension is then pumped to the roof by a hydraulic pump (1000 liters. $\left.\mathrm{h}^{-1}\right)$ to ensure a continuous cycle. Transverse laths are placed on the inclined surface in order to increase the thickness and the mixing of the suspension. Layer thickness increases from $26 \mathrm{~mm}$ behind the lath to $44 \mathrm{~mm}$ in front of the next lath. The suspension volume was 40001 at the beginning of the culture. The volume on the inclined surface was 19001 while the volume in the tank varied around a value of 21001, depending of evaporation and rain.

Supply of carbon dioxide In the $\mathrm{CO}_{2}$ supplemented culture, pure $\mathrm{CO}_{2}$ was added in the suction pipe of the circulation pump. $\mathrm{CO}_{2}$ injection was regulated by a $\mathrm{pH}-$ meter to stabilize the $\mathrm{pH}$ at a value close to 7.5.

Outdoor light intensity measurement The light intensity was measured every 6 minutes by a brightness transmitter 7.1414.51.150 from Thies Clima (Göttingen, Germany). The light intensity was measured in lux and was converted to PAR ( $\mathrm{mmol}$ PAR. $\mathrm{m}^{-2} . \mathrm{s}^{-1}$ ) by dividing lux by 82 . This correction factor was determined by comparing the values of simultaneously measured lux and PAR at the Montrigi weather station (Belgium).

Culture temperature The culture temperature was recorded every 20 minutes by an immersed probe DS1922L from Waranet solutions (Auch, France).

Analytical methods Biomass concentration (g. $\left.\mathrm{l}^{-1}\right)$ was determined daily by measuring the optical density at $750 \mathrm{~nm}$ (A750). After having established the relationship between A750 and dry weight $\left(d w\left[g . l^{-1}\right]=A 750 * 0.35, \mathrm{R}^{2}=0.99\right)$, total biomass in the suspension was calculated, taking into account the suspension volume variations due to evaporation and rain. Net daily algal productivity, including night biomass loss, was estimated from the difference between successive morning values of total biomass divided by the exposed surface $\left(35 \mathrm{~m}^{2}\right)$ of the photobioreactor.

Chlorophyll concentration determination Pigments were extracted from whole cells in ethanol. Extracts were incubated 4 hours on a shaker in presence of small beads and debris were removed by centrifugation at $10,000 \mathrm{~g}$ for $5 \mathrm{~min}$. The $\mathrm{Chl}(a+b)$ concentration was determined according to Lichtenthaler, 1987 with a lambda $20 \mathrm{UV} / \mathrm{V}$ is spectrophotometer (Perkin Elmer, Norwalk, CT).

Chlorophyll fluorescence and $\mathrm{O}_{2}$ evolution measurements Chlorophyll fluorescence emission measurements were made using either a PAM (pulse amplitude modulated) chlorophyll fluorimeter FMS1 from Hansatech instruments (UK) or using an Aquapen AP-C 100 fluorimeter from PSI (Czech Republic).
$\mathrm{F}_{\mathrm{V}} / \mathrm{F}_{\mathrm{M}}$ was determined as $\left(\mathrm{F}_{\mathrm{M}}-\mathrm{F}_{\mathrm{O}}\right) / \mathrm{F}_{\mathrm{M}}$, where $\mathrm{F}_{\mathrm{M}}$ is the maximal fluorescence level determined by applying a saturating pulse under darkness and $\mathrm{F}_{\mathrm{O}}$ is the basal fluorescence level. $\Phi$ PSII was determined as $\left(\mathrm{F}_{\mathrm{M}}^{\prime}-\mathrm{F}_{\mathrm{t}}\right) / \mathrm{F}_{\mathrm{M}}^{\prime}$ where $\mathrm{F}_{\mathrm{M}}^{\prime}$ is the maximal fluorescence level determined by applying a saturating pulse under a particular actinic light intensity and $\mathrm{F}_{\mathrm{t}}$ is the steady-state fluorescence level under this light intensity. NPQ was calculated as $\left(\mathrm{F}_{\mathrm{M}} / \mathrm{F}_{\mathrm{M}}^{\prime}\right)-1$ where $\mathrm{F}_{\mathrm{M}}^{\prime}$ is the maximal fluorescence level obtained by applying a saturating pulse under a particular actinic light intensity and $\mathrm{F}_{\mathrm{M}}$ is the maximal fluorescence level when photoprotective mechanisms are not active.

For the dark-adapted measurements, we used the FMS1 fluorimeter. Cultures were dark-adapted for 30 minutes prior to each measurement and the chlorophyll concentration was adjusted to $8 \mathrm{\mu g} \cdot \mathrm{ml}^{-1}$. The analytical light was provided by light-emitting diodes with an emission maximum at $594 \mathrm{~nm}$. The frequency of measuring flashes was 1500 per second and their integral light intensity was less than $0.1 \mu \mathrm{mol}$ PAR.m ${ }^{-2} \cdot \mathrm{s}^{-1} \cdot \mathrm{F}_{\mathrm{M}}$ and $\mathrm{F}_{\mathrm{M}}^{\prime}$ levels were obtained by applying a pulse of saturating light (6000 $\mathrm{\mu mol}$ PAR. $\mathrm{m}^{-2} \cdot \mathrm{s}^{-1}$ ) provided by a halogen light source. rETR was determined by multiplying the photochemical efficiency of PSII by the light intensity and by 0.5 (assuming that light is equally absorbed by PSII and PSI). Oxygen evolution was simultaneously recorded using a Clark electrode system from Hansatech (UK). The protocol consisted of 6 light periods of $150 \mathrm{sec}$ with light intensities of 50, 160, 300, 550, 750 and $1000 \mu \mathrm{mol}$ PAR. $\mathrm{m}^{-2} . \mathrm{s}^{-1}$ during which we recorded net oxygen evolution. Because mitochondrial respiration is known to increase with light intensity, successive light periods were separated by dark periods of $120 \mathrm{sec}$ during which we recorded the respiration rate. Gross oxygen evolution was defined as $\mathrm{P}_{\text {gross }}=\mathrm{P}_{\text {net }}-\mathrm{R}_{\text {dark }}$ (when using real values of $P_{\text {net }}$ and $R_{\text {dark }}$ ). Light saturating pulses were given every $60 \mathrm{sec}$.

For the light-adapted measurements, we used the Aquapen fluorimeter. These measurements were always made at noon. Cultures were directly taken from the culture (dark-adaptation of $\approx 15$ seconds) and diluted in the cell-free medium (obtained by centrifugation of the culture). Actinic light and saturating pulse were given at $455 \mathrm{~nm}$. The protocol for NPQ and $\Phi$ PSII measurements consisted of a saturating pulse given in darkness followed by 5 different periods of $30 \mathrm{sec}$ with light intensities of

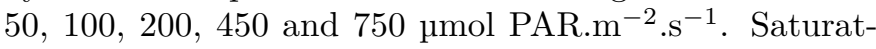
ing pulses were given at the end of each period. For the DCMU-fluorescence rise curves, DCMU was added at a final concentration of $20 \mu \mathrm{M}$ and the light intensity was $2000 \mu \mathrm{mol}$ PAR.m $\mathrm{m}^{-2} \cdot \mathrm{s}^{-1}$.

Typical fluorescence and oxygen evolution measurements curves are shown in Fig. S1.

pH measurement The $\mathrm{pH}$ of the control culture was recorded by a pH-meter BL931700 from Hanna instruments (USA). The $\mathrm{pH}$ of the $\mathrm{CO}_{2}$ supplemented culture was regulated by a $\mathrm{pH}$-meter Evolution deluxe from Dennerle (Germany). 


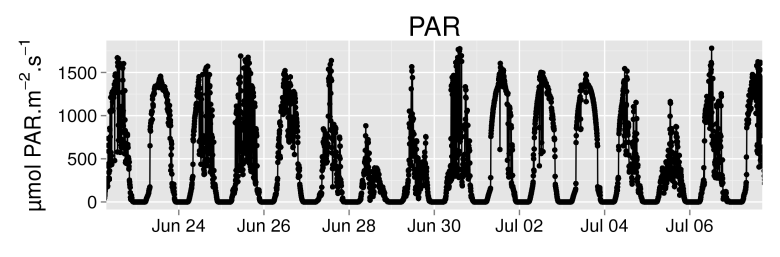

Culture temperature
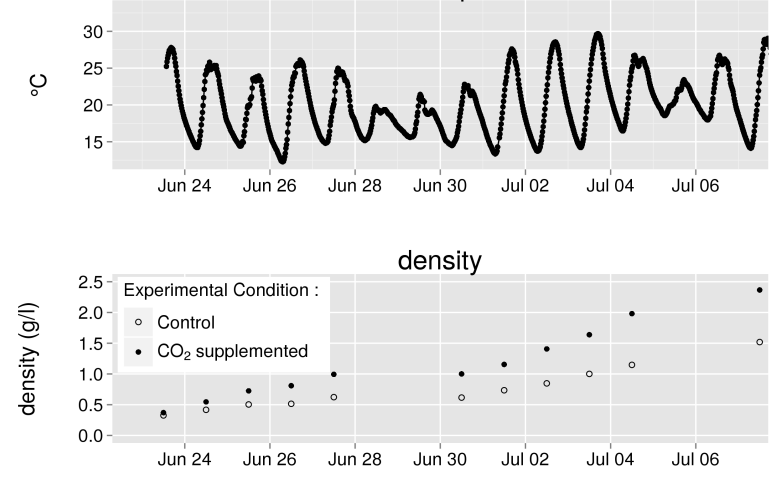

$\mathrm{pH}$

등

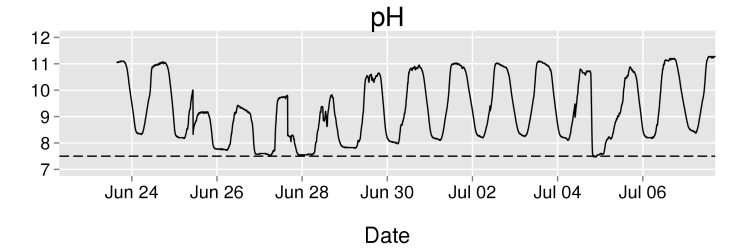

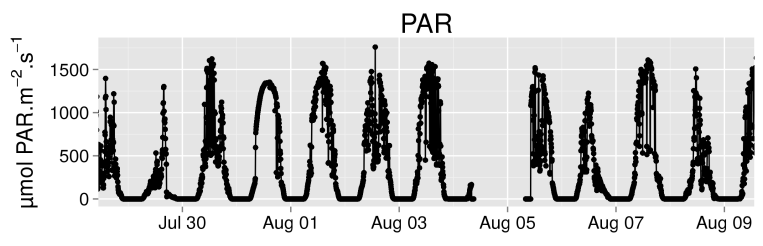
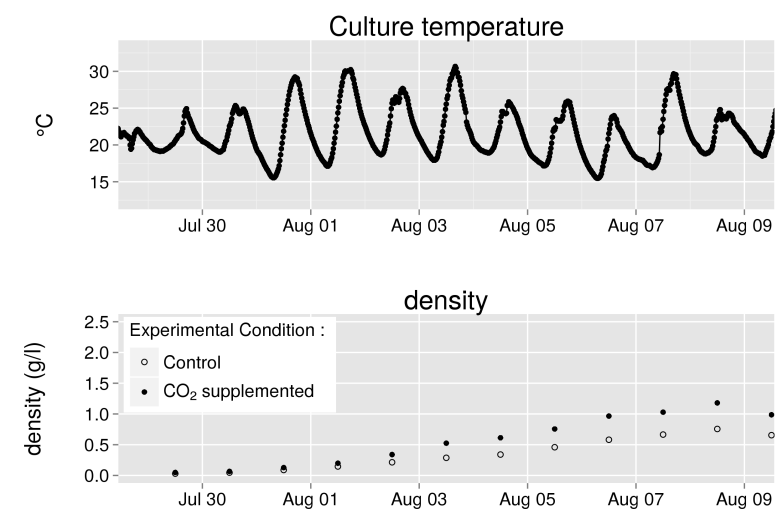

$\mathrm{pH}$

I

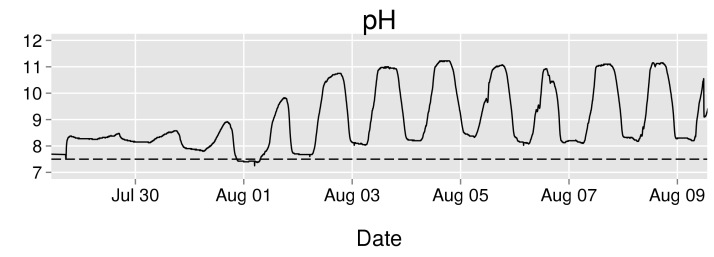

Figure 2: Summary of the data acquired during the two successive experiments. PAR: photosynthetic active radiation measurements from the weather station. The culture temperature was recorded using a probe immersed in the culture. The density of the culture was determined by dividing the total dry biomass by the volume of the culture. The $\mathrm{pH}$ of the control culture was recorded every 5 minutes. The pH of the $\mathrm{CO}_{2}$ supplemented culture was not recorded but was set to 7.5 by injecting pure $\mathrm{CO}_{2}$.

\section{Results and discussion}

\subsection{Productivity and photosynthetic ef- ficiency of Scenedesmus obliquus in high and low $\mathrm{CO}_{2}$ conditions}

In outdoor conditions, irradiance and temperature vary continuously, depending on the weather. During cloudy days, the light intensity and the air temperature are lower than during sunny days. This has an impact on the growth of the culture. We thus continuously recorded irradiance and culture temperature during the whole experiment. A fist experiment was started in June 242014 at a density of $0.4 \mathrm{~g} . \mathrm{l}^{-1}$ and lasted 15 days. In order to obtain data from exponential-phase cultures, a second experiment was started in July 292014 at a lower density of 0.05 g. $l^{-1}$ and lasted 12 days. Fig. 2 summarizes the irradiance, the culture temperature, the culture density and the $\mathrm{pH}$ during these two experiments. In previous studies on thinlayer cascade systems, cultures were usually operated at much higher biomass concentrations (e.g. 1-50 g. $\mathrm{l}^{-1}$ for Masojídek et al. (2011) and Doucha and Lívanský (2006)). The reason why we operated our cultures at lower biomass densities is that the layer thickness of the algal suspension in our system is higher than in other systems $(26-44 \mathrm{~mm}$ in this study in contrast to $6-8 \mathrm{~mm}$ in the two previous studies). All the light being absorbed after a light path of $1 \mathrm{~cm}$ at a density of $1 \mathrm{~g} . \mathrm{l}^{-1}$ (see Fig. S2), operating the system at higher densities would reduce the productivity in our case because the major part of the culture thickness would be in darkness.

Despite a starting density similar at the beginning of the experiments, it is clear that it increased faster in the $\mathrm{CO}_{2}$ supplemented culture than in the control culture. This shows that $\mathrm{CO}_{2}$ availability is a limiting factor in microalgae mass cultures in open thin-layer cascade system.

The $\mathrm{pH}$ varied extensively in the control culture. It increased during the day because of carbon assimilation by photosynthesis. This is explained by the carbon dioxide equilibrium:

$$
\mathrm{CO}_{2}+\mathrm{H}_{2} \mathrm{O} \rightleftharpoons \mathrm{H}_{2} \mathrm{CO}_{3} \rightleftharpoons \mathrm{H}^{+}+\mathrm{HCO}_{3}^{-} \rightleftharpoons \mathrm{CO}_{3}^{2-}+2 \mathrm{H}^{+}
$$

When $\mathrm{CO}_{2}$ is consumed by photosynthesis, $\mathrm{H}^{+}$is released in the medium, thus increasing the $\mathrm{pH}$. During the night, photosynthesis is stopped and $\mathrm{CO}_{2}$ concentration increases due to mitochondrial respiration and to equilibration with atmospheric $\mathrm{CO}_{2}$, leading to a decrease of the $\mathrm{pH}$. At low density $\left(<0.25\right.$ g. $\left.1^{-1}\right)$, the $\mathrm{pH}$ shift during the day gradually increased with cell concentration whereas at higher density $\left(>0.25 \mathrm{~g} . \mathrm{l}^{-1}\right)$, the maximal $\mathrm{pH}$ attained during the day reached a plateau at a value of 11 . The fact that the plateau of 11 was not reached at very low density implies that DIC availability was sufficient to drive photosynthesis and thus we can conclude that $\mathrm{CO}_{2}$ supplementation is needed only at densities higher than 0.2 g. $1^{-1}$.

At $\mathrm{pH}$ higher than 9, it is known that there is virtually no $\mathrm{CO}_{2}$ species and the totality of DIC is present in the form of $\mathrm{HCO}_{3}^{-}$and $\mathrm{CO}_{3}^{2-}$ (Knud-Hansen et al., 1998). The fact 
that Scenedesmus obliquus can grow at such high $\mathrm{pH}$, in contrast with other species like Chlamydomonas reinhardtii, is probably due to the existence of an additional alkaline $\mathrm{HCO}_{3}^{-}$pump in this species (Thielmann et al., 1990). The ability of this species to grow at high $\mathrm{pH}$ is interesting because the majority of contaminants cannot grow and rapidly die at such high $\mathrm{pH}$. The $\mathrm{pH}$ shift could then be used to control contamination in outdoor microalgae mass cultures.

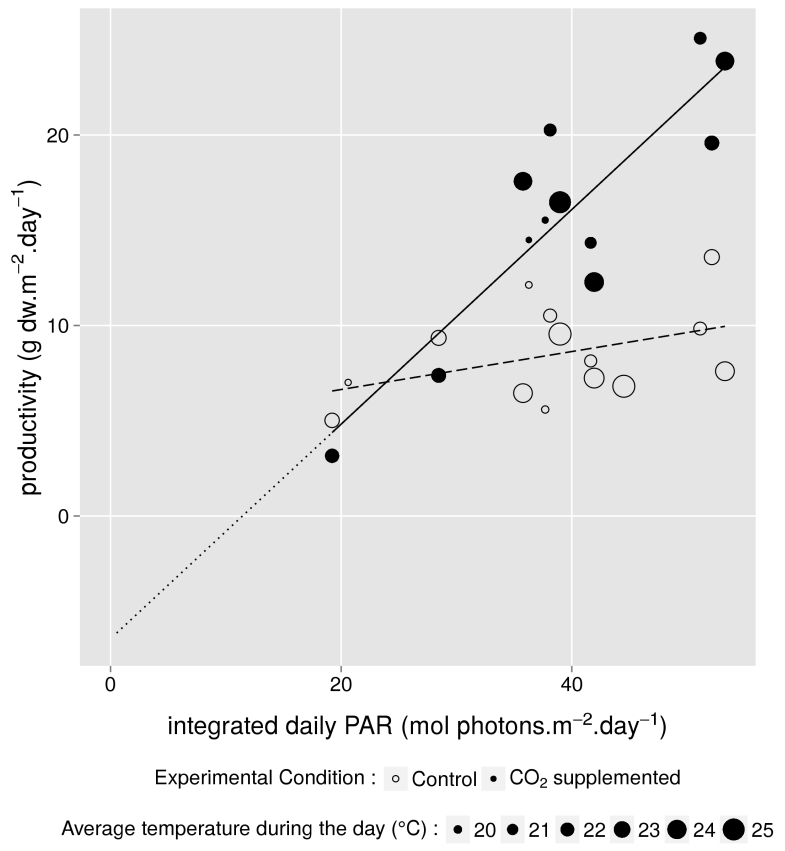

Figure 3: Correlation between productivity and daily integrated PAR for control and $\mathrm{CO}_{2}$ supplemented conditions. The point size represents the average temperature during the day. Regression equation for control condition: $\mathrm{y}=4.65+0.099 \mathrm{x}, \mathrm{R}^{2}=0.18$. Regression equation for $\mathrm{CO}_{2}$ supplemented condition: $\mathrm{y}=-6.44+0.56 \mathrm{x}, \mathrm{R}^{2}=0.77$. The data at very low density in the exponential phase $(<0.2$ g. $1^{-1}$, when the incident light is not limiting) have been considered.

In order to compare the growth of the control and $\mathrm{CO}_{2}$ supplemented cultures, we made a correlation between daily areal productivity (g dry weight. $\mathrm{m}^{-2}$.day ${ }^{-1}$ ) and integrated daily photosynthetic active radiations (mol PAR. $\mathrm{m}^{-2}$.day ${ }^{-1}$ ). Fig 3 shows that during cloudy days, at integrated daily PAR around 20 mol PAR.m ${ }^{-2}$.day ${ }^{-1}$, the productivity of both cultures is similar. This indicates that $\mathrm{CO}_{2}$ supplementation is not necessary when light availability is that low. However, when light supply increases, the productivity of the cultures differs with a near doubled productivity for the $\mathrm{CO}_{2}$ supplemented culture during full sunny days (integrated daily PAR of about 55 mol PAR.m ${ }^{-2}$.day ${ }^{-1}$ ). The correlations between productivity and integrated daily PAR were fitted with a linear equation. The correlation coefficients were good for the $\mathrm{CO}_{2}$ supplemented culture but not for the control culture (0.77 and 0.18 , respectively). Two reasons may explain this fact. First, the relation is probably not linear in the control condition. The relation would probably be linear at low irradiance but would saturate at high irradiance due to limited DIC availability which would prevent an efficient photosynthesis. The second reason is the great variability observed in this condition (i.e. for the same irradiation, the productivity vary extensively). Possible explanations for this variability could have been the light history of the culture or the culture temperature. The latter parameter greatly influences the metabolic reactions of the cell. However, we did not find evidence for a relation between productivity and temperature (shown as the point size in Fig. 3) with the available data.

By extrapolation of the productivity/integrated PAR relationship of the $\mathrm{CO}_{2}$ supplemented culture, the critical irradiance value for zero algal productivity was found to be 11.5 mol PAR.m ${ }^{-2}$.day ${ }^{-1}$. At this irradiance, a compensation point is reached at which an algal culture would not be productive due to a loss of biomass caused by respiration.

We then calculated the photosynthetic efficiencies (PE) of the cultures. PE are usually calculated from the heat of combustion of biomass and the energy content of the photons. Platt and Irwin (1973) developed a relationship between biomass calories on the one hand, and carbon and nitrogen contents on the other hands. As the $\mathrm{C} / \mathrm{N}$ ratio is 8.9 and the carbon content accounts for $52.6 \%$ in the dry weight biomass in Scenedesmus obliquus (Zelibor et al., 1988), the energy of the total biomass was estimated to be 24.6 kJ.g dry weight ${ }^{-1}$. From the productivity/integrated PAR relationships of Fig. 3, we derived that at integrated daily PAR of 24 mol PAR.m ${ }^{-2}$.day ${ }^{-1}$, the productivities and the effective biomass yields of both cultures were similar $\left(7 \pm 2.4 \mathrm{~g} \mathrm{dw} . \mathrm{m}^{-2}\right.$.day ${ }^{-1}$ and $0.29 \pm 0.1 \mathrm{~g} \mathrm{dw} . \mathrm{mol}$ photons $^{-1}$, respectively). Taking into account that the average energy content in the PAR region is $218 \mathrm{~kJ} . \mathrm{mol}$ photons $^{-1}$ (Tilzer et al., 1985), we calculated a PE of 3.3 $\pm 1.1 \%$ for both cultures at this low daily PAR value. The situation is completely different at the highest integrated daily PAR values ( 55 mol PAR.m ${ }^{-2}$.day ${ }^{-1}$ ) because the productivity saturates in the control culture while it does not in the $\mathrm{CO}_{2}$ supplemented culture. At this high irradiance, the productivities were $10 \pm 2.6$ and $24 \pm 3.9 \mathrm{~g}$ $\mathrm{dw} \cdot \mathrm{m}^{-2}$. day ${ }^{-1}$ and the effective biomass yields were 0.18 \pm 0.05 and $0.44 \pm 0.07 \mathrm{~g} \mathrm{dw} . \mathrm{mol}$ photons ${ }^{-1}$ for the control and the $\mathrm{CO}_{2}$ supplemented cultures, respectively. This leads to a PE of $2.1 \pm 0.5$ and $5 \pm 0.8 \%$ for the control and the $\mathrm{CO}_{2}$ supplemented cultures, respectively.

The efficiency of light utilization can also be calculated with another approach, as done in Zijffers et al. (2010), on the basis of the biomass yield on light energy, expressed in $\mathrm{g}$ biomass per mol PAR. By expressing the observed value of this yield as \% of its maximum theoretical value, obtained when the quantum yield of photosynthesis is maximal, an estimation of the actual photosynthetic efficiency is obtained. The maximum theoretical biomass yield is obtained from the stoichiometric reaction equation for formation of biomass and $\mathrm{O}_{2}$ from carbon dioxide, water and the nitrogen source used for cultivation, by admitting that 10 mol PAR are necessary for the evolution of one mol $\mathrm{O}_{2}$. Zijffers et al. found a value of 1.5 g.mol photons ${ }^{-1}$ for Chlorella species when grown on nitrate media. In practice, the actual yield is always lower because: 1) Some light is reflected at the culture surface. 2) Part of the absorbed energy is dissipated as heat due to exposure of algae to supersaturating light levels (typically close to the surface of the culture). 3) Respiration causes some biomass loss, especially during the night in outdoor condition. Night 
Table 1: Summary of the productivities, photosynthetic efficiencies (PE based on biomass heat content), effective biomass yields on light energy and light utilization efficiencies. Low integrated daily PAR $=24{\mathrm{~mol} \mathrm{PAR} . \mathrm{m}^{-2} \text {.day }}^{-1}$. High integrated daily PAR $=55 \mathrm{~mol}$ PAR. $\mathrm{m}^{-2}$.day ${ }^{-1}$. Error ranges represent $95 \%$ confidence intervals around the mean.

\begin{tabular}{|c|c|c|c|}
\hline & low integrated daily PAR & \multicolumn{2}{|c|}{ high integrated daily PAR } \\
\hline & $\begin{array}{l}\text { control and } \mathrm{CO}_{2} \\
\text { supplemented }\end{array}$ & control & $\mathrm{CO}_{2}$ supplemented \\
\hline Productivity (g dw. $\mathrm{m}^{-2}$.day ${ }^{-1}$ ) & $7 \pm 2.4$ & $10 \pm 2.6$ & $24 \pm 3.9$ \\
\hline $\begin{array}{c}\text { PE based on the heat content of biomass } \\
(\%)\end{array}$ & $3.3 \pm 1.1$ & $2.1 \pm 0.5$ & $5 \pm 0.8$ \\
\hline $\begin{array}{c}\text { Biomass yield on light energy ( } \mathrm{g} \text { dw.mol } \\
\text { photons }{ }^{-1} \text { ) }\end{array}$ & $0.29 \pm 0.1$ & $0.18 \pm 0.05$ & $0.44 \pm 0.07$ \\
\hline Light utilization efficiency (\%) & $16 \pm 5.4$ & $10 \pm 2.6$ & $24 \pm 3.9$ \\
\hline
\end{tabular}

respiratory loss has been estimated to represent about $6 \%$ of biomass accumulated during the day with Scenedesmus obliquus (Hindersin et al., 2014). In an extreme case, it attained up to $64 \%$ with a Chlorella species (Masojídek et al., 2011).

The maximum theoretical value of biomass yield on light energy calculated this way depends on the elemental composition of the microalgal species and on the nature of the nitrogen source (ammonium, nitrate or urea). The value calculated by Zijffers et al. was for Chlorella sp. grown on nitrate. However, the Scenedesmus obliquus elemental composition differs from that of Chlorella species (Zelibor et al., 1988; Duboc et al., 1999). Moreover, the nitrogen source of our medium is made of $4 / 5$ of nitrate and $1 / 5$ of ammonium. We thus recalculated the theoretical biomass yield for Scenedesmus obliquus for our medium composition (appendix). Maximum theoretical biomass yield in our culture conditions was 1.82 g.mol photons ${ }^{-1}$. Using this reference value and the effective biomass yields obtained in this study (table 1 ), we obtained values of light utilization efficiencies of $16 \pm 5.4 \%$ under low integrated daily PAR ( 24 mol PAR.m ${ }^{-2}$.day ${ }^{-1}$ ) for both cultures and of $10 \pm 2.6$ and $24 \pm 3.9 \%$ under high integrated daily PAR (55 mol PAR.m ${ }^{-2}$. day ${ }^{-1}$ ) for the control and the $\mathrm{CO}_{2}$ supplemented cultures, respectively.

The productivities, PE, effective biomass yields on light energy and light utilization efficiencies under low and high integrated daily PAR for the control and the $\mathrm{CO}_{2}$ supplemented cultures are summarized in Table 1 . The lower productivities, PE and light utilization efficiencies observed in the control culture at high integrated daily PAR indicate that outdoor mass cultures of Scenedesmus obliquus are limited by the $\mathrm{CO}_{2}$ availability in open thin-layer cultivation systems for biomass densities higher than $0.25 \mathrm{~g} . \mathrm{l}^{-1}$. It may be argued that the high $\mathrm{pH}$ in the control culture ( $\mathrm{pH} 11$ compared to $\mathrm{pH} 7.5$ for the $\mathrm{CO}_{2}$ supplemented culture) may have been responsible for the low performances of this culture. However, both cultures had similar productivities under low integrated daily $\operatorname{PAR}$ (points below $\simeq$ 30 mol PAR. $\mathrm{m}^{-2}$.day ${ }^{-1}$ in Fig. 3$)$ while a high $\mathrm{pH}(\simeq 11)$ was attained in the control culture. This indicates that high $\mathrm{pH}$ was not detrimental and suggests that the lower productivity (and thereby lower PE and light utilization efficiency) of the control culture under higher daily PAR was caused by the limitation in $\mathrm{CO}_{2}$ availability.

Table 2 makes a review of published performances of thin-layer culture systems in terms of areal productivities and photosynthetic efficiencies, with Chlorella sp. or Scenedesmus sp. (mostly obtained in Czech Republic). Our data for Scenedesmus cultures in Liège are in the lower range, likely due both to the relatively high suspension thickness and to the large volume of the tank.

\subsection{Characterisation of the photosyn- thetic apparatus in high and low $\mathrm{CO}_{2}$ conditions}

We then wanted to determine if the productivity differences were accompanied by adaptations of the photosynthetic apparatus to high and low $\mathrm{CO}_{2}$ conditions. For this, we performed fluorescence measurements either on dark-adapted or on light-adapted samples. The dark-adaptation time was 40 min in order to permit the relaxation of dissipation and photoprotective processes. Measurements were carried in presence of saturating DIC concentrations $(10 \mathrm{mM}$ $\left.\mathrm{NaHCO}_{3}\right)$ in order to measure the photosynthetic performances of the samples without limitations. In this manner, we characterised the structural adaptations of the photosynthetic apparatus. In order to characterise the photosynthetic apparatus of the cells as they were in the culture units, we also performed fluorescence measurements on light-adapted samples without $\mathrm{NaHCO}_{3}$ addition. For this, samples were directly taken from the mass culture systems and submitted to the measurements. These measurements were always made at noon. Due to the high sensitivity of the fluorimeter used for light-adapted measurements, samples had to be diluted. This was done in the cell-free medium obtained by centrifugation of the culture in order to keep the DIC concentration unchanged.

\subsubsection{Fluorescence and oxygen evolution mea- surements on dark-adapted samples}

We began our analysis by determining if the two conditions led to differences in the light responses of the photosynthetic apparatus. For this, we established light-response curves for simultaneously measured relative electron transport rate at PSII (rETR) and gross oxygen evolution $\left(\mathrm{VO}_{2}\right)$ in presence of saturating DIC on 40 min dark-adapted samples. No differences in electron transport rate or gross oxygen evolution could be found between the control and the $\mathrm{CO}_{2}$ supplemented cultures for samples taken during the linear growth phase (Fig. 4). This demonstrates that the capacity of high density cultures to realise photosynthesis was not different once the $\mathrm{CO}_{2}$ availability limitation was removed. It is thus tempting to conclude that the structural organisation of the photosynthetic apparatus of Scenedesmus obliquus is not modified by $\mathrm{CO}_{2}$ availability in our mass cultivation system. 
Table 2: Summary of published performances of thin-layer culture systems in terms of areal productivities and photosynthetic efficiencies. ${ }^{a}$ : the way this value was derived is unknown.

\begin{tabular}{|c|c|c|c|c|c|c|c|c|}
\hline Location & Species & Period of the year & $\begin{array}{l}\mathrm{CO}_{2} \\
\text { addition }\end{array}$ & $\begin{array}{l}\text { Culture } \\
\text { thick- } \\
\text { ness } \\
(\mathrm{mm})\end{array}$ & $\begin{array}{l}\text { Surface } \\
\left(\mathrm{m}^{2}\right)\end{array}$ & $\begin{array}{l}\text { Net areal } \\
\text { productivity } \\
\left(\mathrm{g} \cdot \mathrm{m}^{2} \cdot \mathrm{d}^{-1}\right)\end{array}$ & $\begin{array}{c}\text { Photosynthetic } \\
\text { efficiency } \\
\text { based on } \\
\text { PAR } \\
\text { radiations } \\
(\%)\end{array}$ & Reference \\
\hline Czech Republic & Chlorella sp. & August & Yes & 6 & 55 & $\begin{array}{l}22.6 \pm 3.9 \\
19.1 \pm 9.8\end{array}$ & $\begin{array}{l}5.49 \pm 0.89 \\
6.88 \pm 2.94\end{array}$ & Doucha et al. (2005) \\
\hline Czech Republic & $\begin{array}{l}\text { S. obliquus and chlorella } \\
\text { sp. mix }\end{array}$ & la July and August & Yes & $\begin{array}{c}5-7 \\
5-15 \\
6\end{array}$ & 224 & $\begin{array}{c}18.36 \\
21.09 \\
14.9 \pm 6.4\end{array}$ & $\begin{array}{l}- \\
5.4\end{array}$ & Grobbelaar et al. (1995) \\
\hline Czech Republic & S. obliquus & August and September & Yes & $\begin{array}{l}10 \\
40\end{array}$ & 224 & $\begin{array}{l}17.8 \pm 6.2 \\
13.5 \pm 8\end{array}$ & $\begin{array}{l}6.5 \\
4.9\end{array}$ & Doucha and Lívanský (1995) \\
\hline Czech Republic & Chlorella sp. & Sunny days in July & Yes & 6-7 & 224 & 38.2 & 7.05 & $\begin{array}{c}\text { Doucha and } \\
\text { Lívanský (2009), } \\
\text { see also Doucha } \\
\text { and Lívanský } \\
(2015)\end{array}$ \\
\hline Czech Republic & Chlorella sp. & $\begin{array}{l}\text { Sunny days in July, August } \\
\text { and September }\end{array}$ & Yes & $\begin{array}{l}6 \\
6\end{array}$ & $\begin{array}{c}24 \\
224\end{array}$ & $\begin{array}{l}18.7 \pm 5.14 \\
14.3 \pm 4.11\end{array}$ & $\pm 10^{a}$ & Masojídek et al. (2011) \\
\hline $\begin{array}{l}\text { Czech Republic } \\
\text { Southern Greece }\end{array}$ & Chlorella sp. & $\begin{array}{c}\text { July } \\
\text { September } \\
\text { July } \\
\text { October }\end{array}$ & Yes & 6 & 100 & $\begin{array}{l}23.5 \\
11.1 \\
32.2 \\
18.1\end{array}$ & $\begin{array}{l}6.48 \\
5.98 \\
5.42 \\
6.07\end{array}$ & Doucha and Lívanský (2006) \\
\hline Belgium & S. obliquus & July and August & $\begin{array}{l}\text { Yes } \\
\text { No }\end{array}$ & $26-44$ & 35 & $\begin{array}{l}15.8 \pm 6.3 \\
8.5 \pm 2.5\end{array}$ & $\begin{array}{l}4.4 \pm 1.2 \\
2.6 \pm 0.8\end{array}$ & This study \\
\hline
\end{tabular}
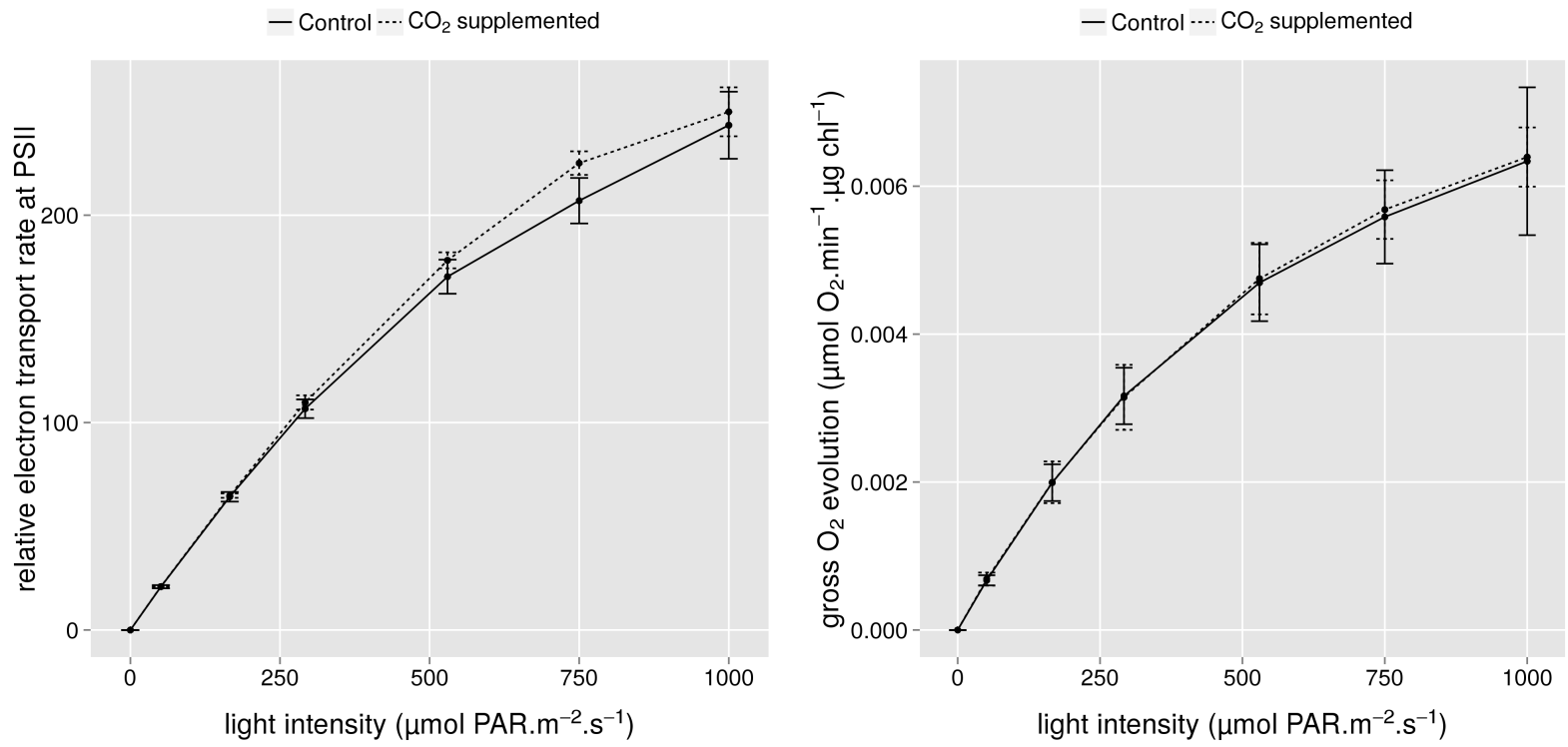

Figure 4: Light-response curves of the relative electron transport rate at PSII (rETR) and of the gross oxygen evolution under different light intensities in high and low $\mathrm{CO}_{2}$ cells. Measurements were performed in presence of $10 \mathrm{mM}$ $\mathrm{NaHCO}_{3}$ after $40 \mathrm{~min}$ of dark-adaptation. Data are average of 5 measurements ( \pm SD) obtained during the linear growth phase (beyond 0.2 g. $1^{-1}$ biomass density) of the two experiments shown in Fig. 2.

It has been shown that $\Phi$ PSII (or ETR) measured in the light was linearly correlated to the quantum yield of oxygen or $\mathrm{CO}_{2}$ uptake in $\mathrm{C} 3$ higher plants when photorespiration was avoided (Genty et al., 1989; Krall and Edwards, 1990; Cornic and Ghashghaie, 1991; Genty and Meyer, 1995; Hymus et al., 1999). This finding permitted the use of simple fluorescence measurements to estimate the $\mathrm{CO}_{2}$ uptake and the productivity of plants.

However, the photosynthetic electron transport chain of microalgae is endowed with great flexibility, due to the existence of auxiliary electron transfer pathways (Peltier et al., 2010), such as electron transfer to $\mathrm{O}_{2}$ at PSI (known as the Mehler reaction) or through PTOX (the plastidial oxidase). Electron transfer to $\mathrm{O}_{2}$ (most probably Mehlertype) has been found earlier to be very effective in the green microalga Chlamydomonas reinhardtii (Sueltemeyer et al., 1986; Bassi et al., 2012). In Scenedesmus, a significant light-dependent $\mathrm{O}_{2}$ uptake has been shown to occur (Rad- mer and Kok, 1976; Radmer and Ollinger, 1980; Flameling and Kromkamp, 1998) although it was not always observed (Heinze et al., 1996). The function of this $\mathrm{O}_{2}$-dependent electron flux is not clear. It could be a way to dissipate reducing power in DIC-limited condition in order to prevent reactive oxygen species (ROS) production which would lead to damages. It could also be a way to produce the ATP needed to concentrate $\mathrm{CO}_{2}$ when its availability is restricted. It follows that electron transport rate estimations, performed fluorimetrically (using ETR as a basis), should not necessarily match photosynthetic rate but may include the rate of electron transport to $\mathrm{O}_{2}$ as sink, even in the absence of significant photorespiration.

This was first investigated here in lab-grown Scenedesmus obliquus (grown in flasks at $200 \mu \mathrm{mol} \mathrm{PAR} \cdot \mathrm{m}^{-2} \cdot \mathrm{s}^{-1}$ ) by plotting ETR and gross oxygen production measured at different light intensities. Measurements were carried out in presence of $\mathrm{NaHCO}_{3}$ to avoid $\mathrm{CO}_{2}$ limitations and pho- 

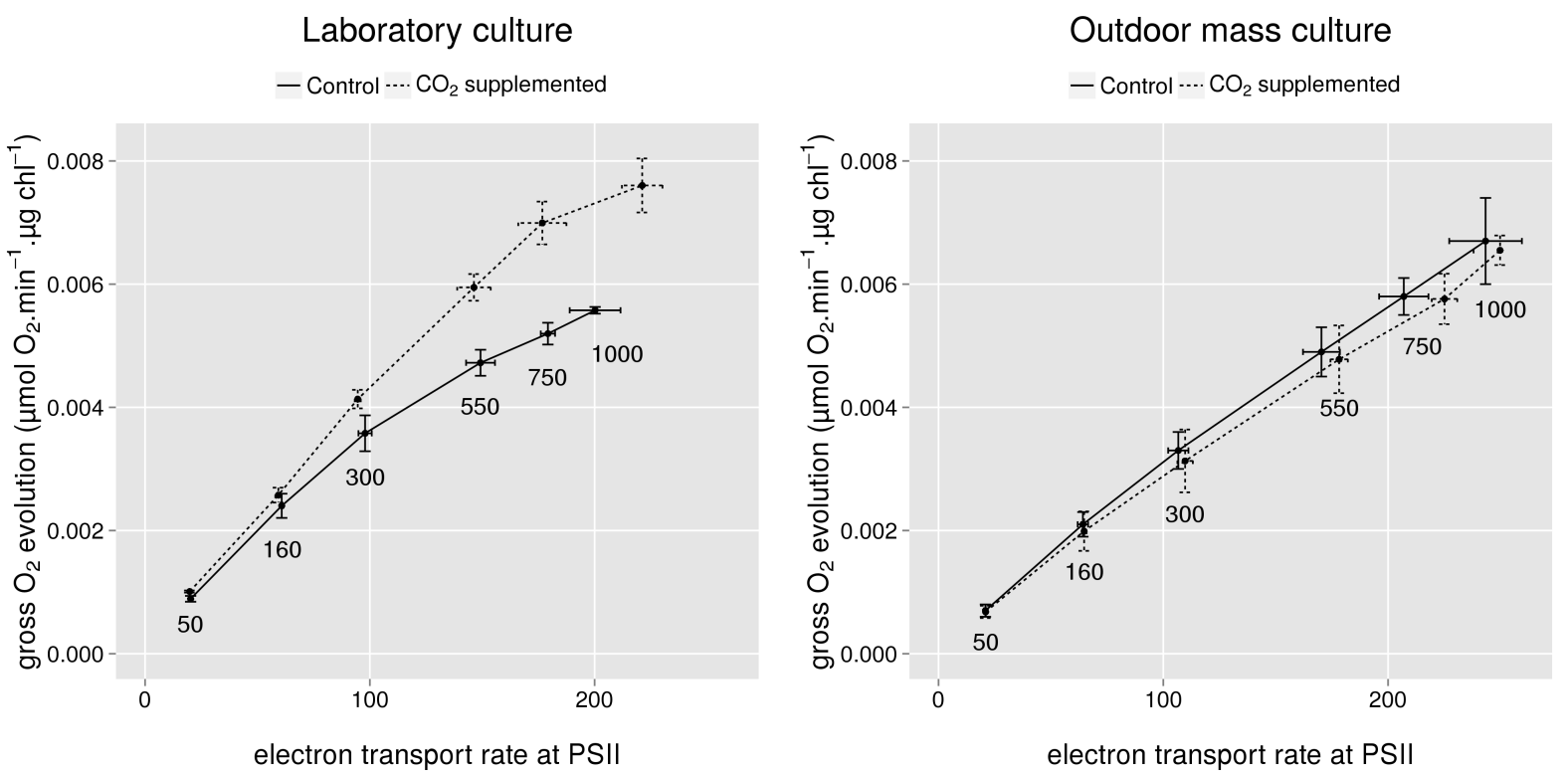

Figure 5: Relationship between relative electron transport rate and gross oxygen evolution measured at different light intensities. Left: Cultures grown in flasks in the laboratory under $200 \mu \mathrm{mol} \mathrm{PAR} . \mathrm{m}^{-2} \cdot \mathrm{s}^{-1}$ continuous illumination in bold $3 \mathrm{~N}$ medium. Cell were grown either with air or with $\mathrm{CO}_{2} 5 \%$ as sparging gas. Data are averages of 3 biological replicates $( \pm \mathrm{SD})$. Right: Outdoor mass cultures. Data are average of 5 measurements $( \pm \mathrm{SD})$ obtained during the linear growth phase of the cultures. Light intensities ( $\mu$ mol PAR. $\left.\mathrm{m}^{-2} \cdot \mathrm{s}^{-1}\right)$ at which measurements were realised are indicated in the figure.

torespiration during the measurements. Fig. 5 shows that the ETR/ $/ \mathrm{VO}_{2}$ relationship in the control and the $\mathrm{CO}_{2}$ supplemented cultures was different, even though the $\mathrm{CO}_{2}$ limitation was removed during measurements.

In both conditions, the relationship was characterized by a curvature which indicates that the flux of electrons is gradually redirected to $\mathrm{O}_{2}$ with increasing irradiance. However, in $\mathrm{CO}_{2}$ supplemented culture, the ETR/ $\mathrm{VO}_{2}$ ratio became higher than in the control culture as the light intensity increased. This indicates that the proportion of electron flux directed to $\mathrm{O}_{2}$ is higher in low $\mathrm{CO}_{2}$ than in high $\mathrm{CO}_{2}$ cells. Absence of $\mathrm{CO}_{2}$ limitation during the measurement indicates that this $\mathrm{O}_{2}$-dependent electron flux is structurally active. It can be concluded that alternative electron flow to $\mathrm{O}_{2}$ occurs in both conditions at high light intensity but is most active after growth in low $\mathrm{CO}_{2}$ condition.

However, this was not the case for the outdoor mass cultures for which the ETR/ $\mathrm{VO}_{2}$ relationships were characterised by a straight line for both conditions. This observation indicates that, if we except the photorespiration which was not assessed in this study, alternative electron flow to $\mathrm{O}_{2}$ probably either did not occur in outdoor mass culture or was independent of $\mathrm{CO}_{2}$ supply.

The reason for the absence of differences in the $\mathrm{ETR} / \mathrm{VO}_{2}$ relationship for the outdoor mass culture compared to the cultures grown in the laboratory must be due to the culture conditions which were very different. While the culture grown in the laboratory was cultivated at a low density and under continuous illumination, the outdoor mass culture was characterised by a higher density, day/night cycles and light/dark cycles during the day. The effect of these factors on the ETR/ $\mathrm{VO}_{2}$ relationship remains to be investigated.

\subsubsection{Fluorescence measurements on light- adapted samples}

We then measured the evolution of the PSII operating photochemical efficiency ( $\Phi$ PSII) under different light intensities on light-adapted samples, i.e. after a dark period as short as $15 \mathrm{~s}$ which was necessary for transfer to the fluorimeter (Fig. 6). At low density during the first four days, there was no difference between the two cultures, suggesting that the control culture was not limited by DIC availability. This observation is confirmed by the small $\mathrm{pH}$ shift observed during the first four days (Fig. 2, second experiment). The fact that the maximal $\mathrm{pH} 11$ was not attained at these days indicates that DIC availability was sufficient to sustain photosynthesis.

From day 5 to day 11, the general trend was that $\Phi$ PSII was always lower in the control culture than in the $\mathrm{CO}_{2}$ supplemented culture, suggesting that DIC availability became too low to sustain an efficient photosynthesis in the former culture. Day to day variations in $\Phi$ PSII responses were observed, but we could not correlate them with the measured variables (temperature, daily PAR or productivities). More extended data sets would be necessary in order to analyse further the relationship between $\Phi$ PSII and the culture history.

Noteworthy, Fig. 6 also shows that the maximal $\Phi$ PSII values $\left(\mathrm{F}_{\mathrm{V}} / \mathrm{F}_{\mathrm{M}}\right.$ obtained in the dark) became lower in the control culture compared to the $\mathrm{CO}_{2}$-supplemented culture starting from day 5 , with this difference varying from one day to another. Low $\mathrm{F}_{\mathrm{V}} / \mathrm{F}_{\mathrm{M}}$ values in microalgae mass cultures are generally taken as indicating some degree of photoinhibition. Midday PSII photoinhibition of $\approx 30 \%$ has been described in outdoor mass culture with Arthrospira platensis (Vonshak et al., 1994; Vonshak et al., 1996; Torzillo et al., 1996; Torzillo et al., 1998) and Chlorella (Masojídek et al., 2011). Most photoinhibition 

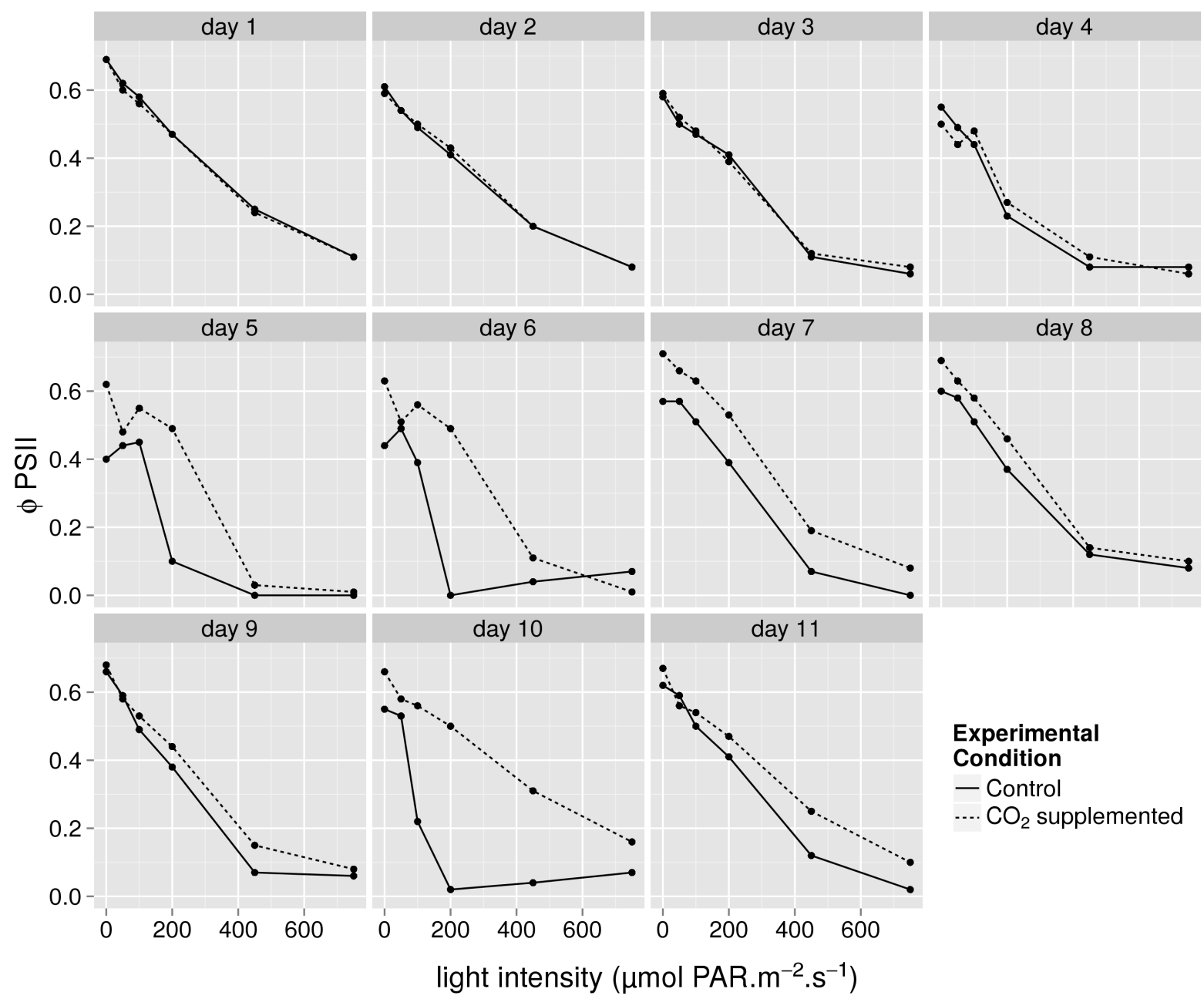

Figure 6: Evolution of the PSII photochemical efficiency (\$PSII) under different light intensities during the course of the culture. Data shown are from experiment 2. A similar trend was observed for experiment 1.

studies conducted on Scenedesmus obliquus have been performed on cultures grown in the laboratory (Flameling and Kromkamp, 1997; Yang and Gao, 2003). Here, we show that a decreased $\mathrm{F}_{\mathrm{V}} / \mathrm{F}_{\mathrm{M}}$ also occurs in Scenedesmus obliquus grown in outdoor mass cultures and that this photoinhibition is influenced by DIC availability. It must be noted, however, that differences in $\mathrm{F}_{\mathrm{V}} / \mathrm{F}_{\mathrm{M}}$ and $\Phi$ PSII found here in relation to $\mathrm{CO}_{2}$ supply were suppressed after dark-adaptation (40 min) followed by $\mathrm{NaHCO}_{3}$ addition in the measurement cuvette (see Fig. 4).

A decreased photochemical efficiency (\$PSII) in the control culture has to be compensated by dissipative mechanisms such as increased heat dissipation in the antennas (or energy dependent quenching $\mathrm{qE}$ NPQ). This process can be highlighted by monitoring the decrease of the $\mathrm{F}_{\mathrm{M}}$ fluorescence level (NPQ) following illumination. We thus measured NPQ of samples directly taken from the cultures and exposed to different light intensities (Fig. 7). We checked that the fluorescence quenching observed here was relaxed in a few seconds, indicating that this quenching was due to qE NPQ and not to photoinhibition or state transitions. Fig. 7 shows that this NPQ was higher in the control culture than in the $\mathrm{CO}_{2}$ supplemented culture. This demonstrates that a part of the absorbed light energy which could not be used for $\mathrm{CO}_{2}$ assimilation due to its reduced availability in the control culture was dissipated as heat.

These measurements showed that heat dissipation for a particular light intensity is higher in the control culture compared to the $\mathrm{CO}_{2}$ supplemented culture. However, although the cultures were inoculated at the same density, the density became different as the time elapses due to the different growth rates of the cultures (i.e. $\mathrm{CO}_{2}$ supplemented culture density was higher than control culture density for each particular day). It follows that the average light intensity in the thickness of the cultivation system was higher in the control culture than for the $\mathrm{CO}_{2}$ supplemented culture for the same incident light intensity and thus, differences in effective $\mathrm{qE}$ NPQ between the two culture must have been even higher than experimentally estimated on the basis of equal excitation.

A decreased PSII antenna size has been described in low $\mathrm{CO}_{2}$ condition compared to high $\mathrm{CO}_{2}$ condition in Chlamydomonas reinhardtii cultures grown in laboratory (Berger et al., 2014). This phenomenon can be interpreted as a way to avoid on over-reduction of the electron transport chain in condition of restricted DIC availability. We thus determined if the control culture had a reduced PSII antenna size compared to the $\mathrm{CO}_{2}$ supplemented culture. For this, we measured the functional PSII antenna size by measuring the halftime of the time course of the DCMU fluorescence rise. In presence of this inhibitor, the fluo- 


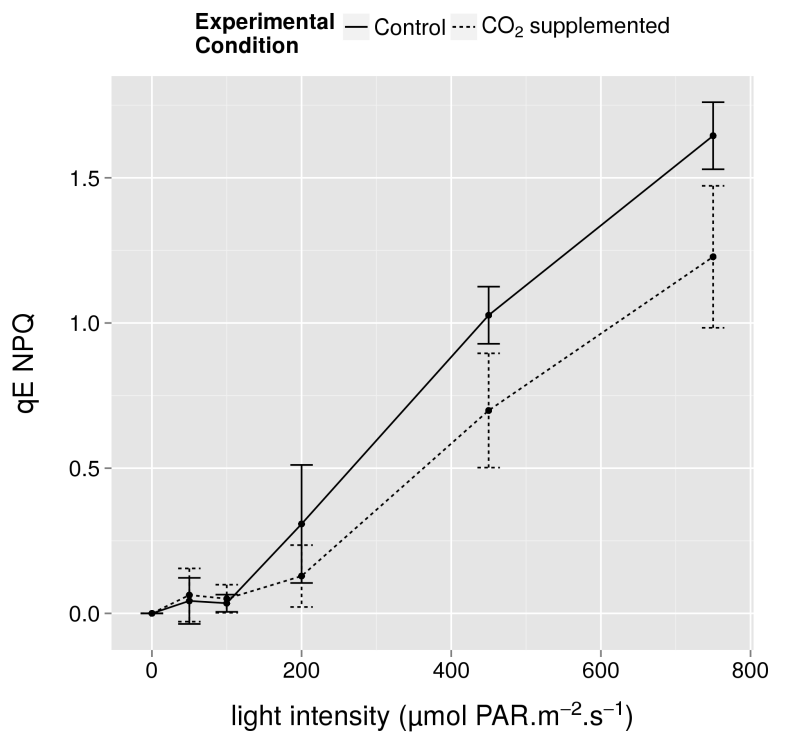

Figure 7: Evolution of the energy-dependent nonphotochemical quenching ( $\mathrm{qE} N \mathrm{NQ}$ ) under different light intensities showing a higher $q \mathrm{E} N \mathrm{NQ}$ in the control culture than in the $\mathrm{CO}_{2}$ supplemented culture at light intensities higher than $200 \mathrm{\mu mol} \mathrm{PAR} \cdot \mathrm{m}^{-2} \cdot \mathrm{s}^{-1}$. Data are averages of 6 days $( \pm \mathrm{SD})$ during the linear growth phase of the second culture, when DIC availability was limiting for the control culture.

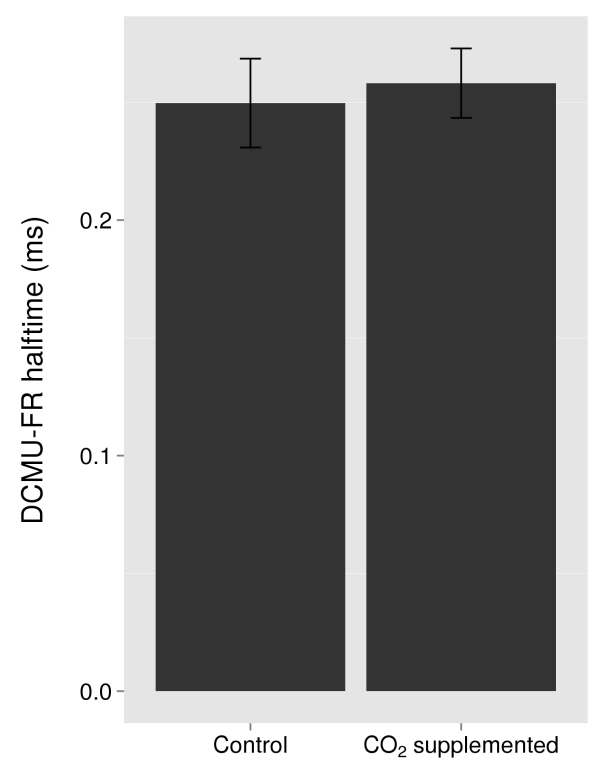

Figure 8: Average of the halftime of the DCMU-FR curve. The halftime is the time when the normalised variable fluorescence level reaches 0.5. Data are averages of 14 measurements $( \pm \mathrm{SD})$ from experiments 1 and 2 during linear growth phase.

rescence rise represents the photochemical reduction of $\mathrm{Q}_{\mathrm{A}}$ without influence of its reoxidation by plastoquinones. This measurement has been shown to be a good indicator of the PSII antenna size in Chlamydomonas reinhardtii (de Marchin et al., 2014). We couldn't notice significant difference in the halftime between the control and the $\mathrm{CO}_{2}$ supplemented culture during linear growth phase (Fig. 8).
This indicates that the PSII functional antenna size is not modulated by $\mathrm{CO}_{2}$ availability in Scenedesmus obliquus in outdoor mass culture conditions.

\section{Conclusion}

In this study, we showed that the productivity of outdoor mass cultures of Scenedesmus obliquus is limited by the $\mathrm{CO}_{2}$ availability in open thin-layer cultivation systems at high light irradiance for biomass densities higher than 0.25 g. $1^{-1}$. This limitation is suppressed by injecting carbon dioxide in the culture. Under low integrated daily PAR (around 20-25 mol PAR.m ${ }^{-2}$.day ${ }^{-1}$ ), both cultures were characterised by a productivity of $7 \pm 2.4 \mathrm{~g} \mathrm{dw} \cdot \mathrm{m}^{-2}$.day ${ }^{-1}$ and a PE of $3.3 \pm 1.1 \%$ (value based on the PAR solar radiation energy). In contrast, under the highest integrated daily PAR (55 mol PAR.m ${ }^{-2}$.day ${ }^{-1}$ ), the productivities and PE were very different with values of $10 \pm 2.6$ and 24 $\pm 3.9 \mathrm{~g} \mathrm{dw} . \mathrm{m}^{-2}$. day ${ }^{-1}$ and $2.1 \pm 0.5$ and $5 \pm 0.8 \%$ for the control and the $\mathrm{CO}_{2}$ supplemented cultures, respectively. From fluorescence and oxygen evolution measurements on dark-adapted samples, we couldn't find significant differences in the ETR and oxygen evolution light saturation curves between high and low $\mathrm{CO}_{2}$ cultures. In contrast to cultures grown in the laboratory under constant light, there was no difference in the $\mathrm{ETR} / \mathrm{VO}_{2}$ relationship between the two cultures. This suggests that light-dependent $\mathrm{O}_{2}$ uptake is not enhanced by DIC limitation in outdoor mass cultures. We conclude that the structural organisation of the photosynthetic apparatus is not affected by the $\mathrm{CO}_{2}$ availability in outdoor mass cultures in this species. From fluorescence measurements on light-adapted samples, we found a lowest PSII photosynthetic efficiency and a higher NPQ for the low $\mathrm{CO}_{2}$ culture which could be explained by an increased heat-dissipation and photoinhibition in this culture. In contrast, we couldn't find any differences in the PSII antenna size between the two conditions. The lowest productivity of the low $\mathrm{CO}_{2}$ culture is paralleled by a decreased PSII photochemical efficiency and an increased heat-dissipation. These results exemplify the fact that high density microalgae mass cultures should be $\mathrm{CO}_{2}$ supplemented to ensure efficient light utilisation and biomass productivity.

\section{$5 \quad$ Appendix}

\subsection{Maximal theoretical biomass yield}

The maximum theoretical biomass yield on light energy was calculated following Zijffers et al. (2010). Assuming an elemental composition of $\mathrm{CH}_{1.64} \mathrm{O}_{0.49} \mathrm{~N}_{0.10}$ for Scenedesmus obliquus (Zelibor et al., 1988), the stoichiometric reaction equation for the formation of biomass on carbon dioxide, water and nitrogen source is the following:

- When grown on nitrate:

$$
\begin{aligned}
& 1 \mathrm{CO}_{2}(\mathrm{~g})+0.87 \mathrm{H}_{2} \mathrm{O}(\mathrm{l})+0.10 \mathrm{NO}_{3}^{-}(\mathrm{aq}) \\
\rightarrow & \mathrm{CH}_{1.64} \mathrm{O}_{0.49} \mathrm{~N}_{0.10}(\mathrm{~s})+1.29 \mathrm{O}_{2}(\mathrm{~g})+0.10 \mathrm{OH}^{-}(\mathrm{aq})
\end{aligned}
$$


- When grown on ammonium:

$$
\begin{aligned}
& 1 \mathrm{CO}_{2}(\mathrm{~g})+0.67 \mathrm{H}_{2} \mathrm{O}(\mathrm{l})+0.10 \mathrm{NH}_{4}^{+}(\mathrm{aq}) \\
\rightarrow & \mathrm{CH}_{1.64} \mathrm{O}_{0.49} \mathrm{~N}_{0.10}(\mathrm{~s})+1.09 \mathrm{O}_{2}(\mathrm{~g})+0.10 \mathrm{H}^{+}(\mathrm{aq})
\end{aligned}
$$

Assuming that the quantum yield of the light reactions is $0.1 \mathrm{~mol} \mathrm{O}_{2}$ evolved per mol of photons and that the molecular mass of a C-mol biomass of Scenedesmus obliquus is 22.88 g.mol ${ }^{-1}, 12.9$ and 10.9 mol of photons are needed to produce one $\mathrm{C}$-mol of biomass when grown on nitrate and ammonium, respectively. This leads to a theoretical biomass yield of 1.77 and 2.06 g.mol photons ${ }^{-1}$ when grown on nitrate and ammonium, respectively.

\section{Acknowledgements}

Thomas de Marchin thanks the F.R.I.A. for the award of a fellowship. Fabrice Franck is research director of the Fonds de la Recherche Scientifique F.R.S-FNRS. The authors thank Dr Thomas Gerards for his help and advices for experimentation with the outdoor thin-layer cascade photobioreactors.

\section{References}

Baker, N. R. (2008). "Chlorophyll fluorescence: a probe of photosynthesis in vivo". In: Annu. Rev. Plant Biol. 59, pp. 89-113.

Bassi, R., Cardol, P., Choquet, Y., De Marchin, T., Economou, C., Franck, F., Goldschmidt-Clermont, M., Jacobi, A., Loizeau, K., Mathy, G., Plancke, C., Posten, C., Purton, S., Remacle, C., Vejrazka, C., Wei, L., and Wollman, F.-A. (2012). "13 Finding the bottleneck: A research strategy for improved biomass production". In: Microalgal Biotechnology: Integration and Economy. Ed. by C. Posten and C. Walter. Berlin, Boston: DE, pp. 227252.

Béchet, Q., Shilton, A., and Guieysse, B. (2013). "Modeling the effects of light and temperature on algae growth: State of the art and critical assessment for productivity prediction during outdoor cultivation". In: Biotechnology Advances 31.8, pp. 1648-1663.

Berger, H., Blifernez-Klassen, O., Ballottari, M., Bassi, R., Wobbe, L., and Kruse, O. (2014). "Integration of Carbon Assimilation Modes with Photosynthetic Light Capture in the Green Alga Chlamydomonas reinhardtii". In: Molecular Plant 7.10, pp. 1545-1559.

Cornic, G. and Ghashghaie, J. (1991). "Effect of temperature on net CO2 assimilation and photosystem II quantum yield of electron transfer of French bean (Phaseolus vulgaris L.) leaves during drought stress". In: Planta 185.2, pp. 255-260.

de Marchin, T., Ghysels, B., Nicolay, S., and Franck, F. (2014). "Analysis of PSII antenna size heterogeneity of Chlamydomonas reinhardtii during state transitions". In: Biochimica et Biophysica Acta (BBA) - Bioenergetics 1837.1, pp. 121-130.
Doucha, J. and Lívanský, K. (2006). "Productivity, $\mathrm{CO} 2 / \mathrm{O} 2$ exchange and hydraulics in outdoor open high density microalgal (Chlorella sp.) photobioreactors operated in a Middle and Southern European climate". en. In: Journal of Applied Phycology 18.6, pp. 811-826.

Doucha, J. and Lívanský, K. (2009). "Outdoor open thinlayer microalgal photobioreactor: potential productivity". In: Journal of applied phycology 21.1, pp. 111-117.

Doucha, J. and Lívanský, K. (2015). "Erratum to: Outdoor open thin-layer microalgal photobioreactor: potential productivity". In: Journal of Applied Phycology 27.2, pp. 1043-1043.

Doucha, J. and Livansky, K. (1999). Process of outdoor thin-layer cultivation of microalgae and blue-green algae and bioreactor for performing the process. US Patent 5,981,271. Google Patents.

Doucha, J. and Lívanský, K. (1995). "Novel outdoor thinlayer high density microalgal culture system: Productivity and operational parameters". In: A1golog. Stud., Stuttgart 76, pp. 129-147.

Doucha, J., Straka, F., and Lívanský, K. (2005). "Utilization of flue gas for cultivation of microalgae Chlorella (sp.) in an outdoor open thin-layer photobioreactor". en. In: Journal of Applied Phycology 17.5, pp. 403-412.

Duboc, P., Marison, I., Von Stockar, U., and Kemp, R. (1999). "Handbook of thermal analysis and calorimetry". In: Elsevier, pp. 267-365.

Flameling, I. A. and Kromkamp, J. (1998). "Light dependence of quantum yields for PSII charge separation and oxygen evolution in eucaryotic algae". In: Limnology and oceanography 43, pp. 284-297.

Flameling, I. A. and Kromkamp, J. (1997). "Photoacclimation of Scenedesmus protuberans (Chlorophyceae) to fluctuating irradiances simulating vertical mixing". In: Journal of plankton research 19.8, pp. 1011-1024.

Genty, B., Briantais, J.-M., and Baker, N. R. (1989). "The relationship between the quantum yield of photosynthetic electron transport and quenching of chlorophyll fluorescence". In: Biochimica et Biophysica Acta (BBA) - General Subjects 990.1, pp. 87-92.

Genty, B. and Meyer, S. (1995). "Quantitative mapping of leaf photosynthesis using chlorophyll fluorescence imaging". In: Functional Plant Biology 22.2, pp. 277-284.

Grobbelaar, J. U., Nedbal, L., Tichy, L., and Setlik, L. (1995). "Variation in some photosynthetic characteristics of microalgae cultured in outdoor thin-layered sloping reactors". In: Journal of applied phycology 7.2, pp. 175184.

Heinze, I., Dau, H., and Senger, H. (1996). "The relation between the photochemical yield and variable fluorescence of photosystem II in the green alga Scenedesmus obliquus". In: Journal of Photochemistry and Photobiology B: Biology 32.1, pp. 89-95.

Hindersin, S., Leupold, M., Kerner, M., and Hanelt, D. (2014). "Key parameters for outdoor biomass production of Scenedesmus obliquus in solar tracked photobioreactors". In: Journal of Applied Phycology 26.6, pp. 23152325.

Hymus, G. J., Ellsworth, D. S., Baker, N. R., and Long, S. P. (1999). "Does Free-Air Carbon Dioxide Enrichment Affect Photochemical Energy Use by Evergreen Trees in Different Seasons? A Chlorophyll Fluorescence Study 
of Mature Loblolly Pine". In: Plant Physiology 120.4, pp. 1183-1192.

Jerez, C., Navarro, E., Malpartida, I., Rico, R., Masojídek, J., Abdala, R., and Figueroa, F. (2014). "Hydrodynamics and photosynthesis performance of Chlorella fusca (Chlorophyta) grown in a thin-layer cascade (TLC) system". In: Aquatic Biology 22, pp. 111-122.

Kajan, M., Tichý, V., and Simmer, J. (1994). "Productivity of algae in different culture systems". en. In: Algological Studies/Archiv für Hydrobiologie, Supplement Volumes, pp. 111-117.

Knud-Hansen, C. F., McElwee, K., Baker, J., and Clair, D. (1998). Pond fertilization: ecological approach and practical application. Pond Dynamics/Aquaculture Collaborative Research Support Program, Oregon State University Corvallis, Oregon.

Krall, J. P. and Edwards, G. E. (1990). "Quantum yields of photosystem II electron transport and carbon dioxide fixation in C4 plants". In: Functional Plant Biology 17.5, pp. $579-588$.

Lichtenthaler (1987). "Chlorophylls and carotenoids: pigment of photosynthetic biomembranes." In: Methods Enzymol. 148, pp. 350-382.

Livansky, K. (2000). "Comparison of continuous and stepwise control of $\mathrm{CO} 2$ supply into outdoor open thin-layer algal culture units". eng. In: Archiv für Hydrobiologie. Supplementband, Algological studies 131, pp. 119-129.

Lívanský, K. and Doucha, J. (1996). "CO2 and O2 gas exchange in outdoor thin-layer high density microalgal cultures". In: Journal of Applied Phycology 8.4-5, pp. 353-358.

Masojídek, J., Vonshak, A., and Torzillo, G. (2010). "Chlorophyll fluorescence applications in microalgal mass cultures". In: Chlorophyll a Fluorescence in Aquatic Sciences: Methods and Applications, pp. 277-292.

Masojídek, J., Kopecký, J., Giannelli, L., and Torzillo, G. (2011). "Productivity correlated to photobiochemical performance of Chlorella mass cultures grown outdoors in thin-layer cascades". In: Journal of industrial microbiology \& biotechnology 38.2, pp. 307-317.

Moroney, J. V., Ma, Y., Frey, W. D., Fusilier, K. A., Pham, T. T., Simms, T. A., DiMario, R. J., Yang, J., and Mukherjee, B. (2011). "The carbonic anhydrase isoforms of Chlamydomonas reinhardtii: intracellular location, expression, and physiological roles". In: Photosynthesis Research 109, pp. 133-149.

Peltier, G., Tolleter, D., Billon, E., and Cournac, L. (2010). "Auxiliary electron transport pathways in chloroplasts of microalgae". In: Photosynthesis Research 106.1, pp. 1931.

Platt, T. and Irwin, B. (1973). "Caloric content of phytoplankton". In: Limnology and Oceanography 18.2, pp. 306-310.

Radmer, R. J. and Kok, B. (1976). "Photoreduction of O2 primes and replaces CO2 assimilation". In: Plant physiology 58.3, pp. 336-340.

Radmer, R. and Ollinger, O. (1980). "Light-driven uptake of oxygen, carbon dioxide, and bicarbonate by the green alga Scenedesmus". In: Plant physiology 65.4, pp. 723729.

Šetlík, I., Šust, V., and Málek, I. (1970). "Dual Purpose Open Circulation Units for Large Scale Culture of Algae in Temperate Zones. I. Basic Design Considera- tions and Scheme of a Pilot Plant". en. In: Algological Studies/Archiv für Hydrobiologie, Supplement Volumes, pp. 111-164.

Sueltemeyer, D., Klug, K., and Fock, H. (1986). "Effect of photon fluence rate on oxygen evolution and uptake by Chlamydomonas reinhardtii suspensions grown in ambient and CO2-enriched air". In: Plant physiology 81.2, p. 372 .

Thielmann, J., Tolbert, N., Goyal, A., and Senger, H. (1990). "Two systems for concentrating CO2 and bicarbonate during photosynthesis by Scenedesmus". In: Plant physiology 92.3, p. 622.

Tilzer, M. M., Bodungen, B. v., and Smetacek, V. (1985). "Light-Dependence of Phytoplankton Photosynthesis in the Antarctic Ocean: Implications for Regulating Productivity". In: Antarctic Nutrient Cycles and Food Webs. Ed. by P. W. R. Siegfried, D. P. R. Condy, and D. R. M. Laws. Springer Berlin Heidelberg, pp. 60-69.

Tocquin, P., Fratamico, A., and Franck, F. (2012). "Screening for a low-cost Haematococcus pluvialis medium reveals an unexpected impact of a low $\mathrm{N} / \mathrm{P}$ ratio on vegetative growth". In: Journal of Applied Phycology 24.3, pp. $365-373$.

Torzillo, G., Accolla, P., Pinzani, E., and Masojidek, J. (1996). "In situ monitoring of chlorophyll fluorescence to assess the synergistic effect of low temperature and high irradiance stresses in Spirulina cultures grown outdoors in photobioreactors". In: Journal of Applied Phycology 8.4, pp. 283-291.

Torzillo, G., Bernardini, P., and Masojídek, J. (1998). "online monitoring of chlorophyll fluorescence to assess the extent of photoinhibition of photosynthesis induced by high oxygen concentration and low temperature and its effect on the productivity of outdoor cultures of spirulina platensis (cyanobacteria)". In: Journal of phycology 34.3, pp. $504-510$.

Vonshak, A., Torzillo, G., Accolla, P., and Tomaselli, L. (1996). "Light and oxygen stress in Spirulina platensis (cyanobacteria) grown outdoors in tubular reactors". In: Physiologia Plantarum 97.1, pp. 175-179.

Vonshak, A., Torzillo, G., and Tomaseli, L. (1994). "Use of chlorophyll fluorescence to estimate the effect of photoinhibition in outdoor cultures of Spirulina platensis". In: Journal of applied phycology 6.1, pp. 31-34.

Yang, Y. and Gao, K. (2003). "Effects of CO2 concentrations on the freshwater microalgae, Chlamydomonas reinhardtii, Chlorella pyrenoidosa and Scenedesmus obliquus (Chlorophyta)". In: Journal of Applied Phycology 15.5, pp. 379-389.

Yun, Y.-S. and Park, J. M. (2003). "Kinetic modeling of the light-dependent photosynthetic activity of the green microalga Chlorella vulgaris". In: Biotechnology and Bioengineering 83.3.

Zelibor, J. L., Romankiw, L., Hatcher, P. G., and Colwell, R. R. (1988). "Comparative analysis of the chemical composition of mixed and pure cultures of green algae and their decomposed residues by $13 \mathrm{C}$ nuclear magnetic resonance spectroscopy". In: Applied and environmental microbiology 54.4, pp. 1051-1060.

Zijffers, J.-W. F., Schippers, K. J., Zheng, K., Janssen, M., Tramper, J., and Wijffels, R. H. (2010). "Maximum Photosynthetic Yield of Green Microalgae in Photobioreactors". In: Marine Biotechnology 12.6, pp. 708-718. 
Zittelli, G. C., Biondi, N., Rodolfi, L., and Tredici, M. R. 7 Supplemental data

(2013). "Photobioreactors for Mass Production of Microalgae". In: Handbook of Microalgal Culture. Ed. by A. R. P. D. Emeritus and Q. H. Ph.D. John Wiley \& Sons, Ltd, pp. 225-266.

\subsection{Example of typical fluorescence and oxygen evolution measurements}

Figure S1.

\subsection{Light attenuation in the thickness of the suspension}

Figure S2.

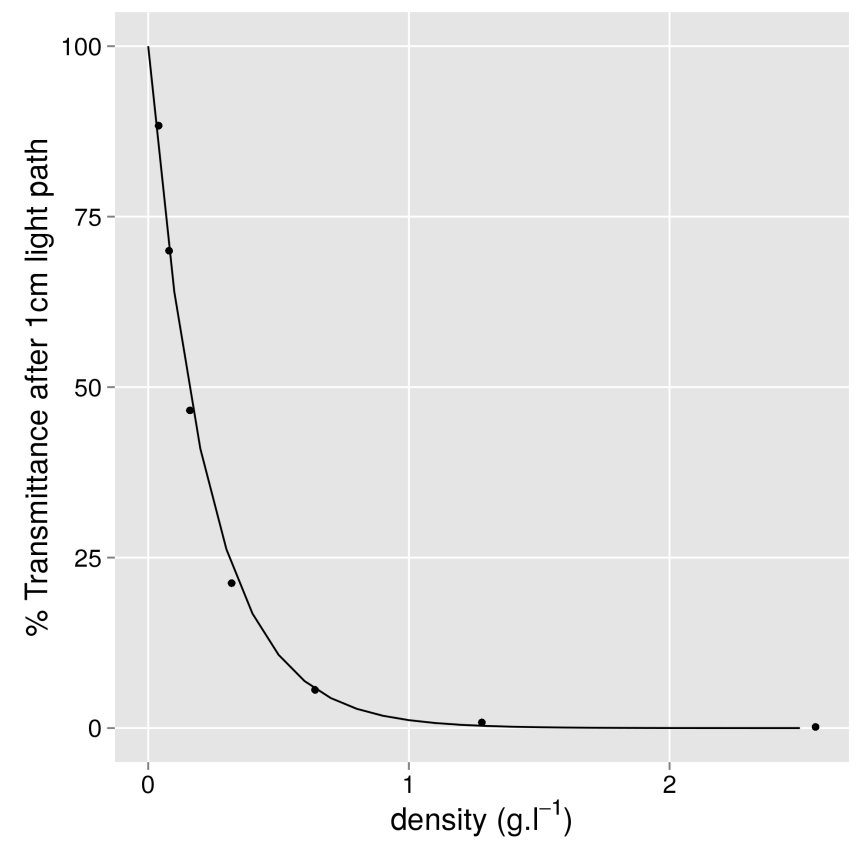

Figure S2: Transmittance (\%) after $1 \mathrm{~cm}$ light path. Transmittance was determined by averaging the light transmission in the PAR region (400-700nm) of culture samples at densities ranging from 0.05 to 2.5 g. $\mathrm{l}^{-1}$. Line: fit of the hyperbolic Beer-Lambert law (Yun and Park, 2003; Béchet et al., 2013). 


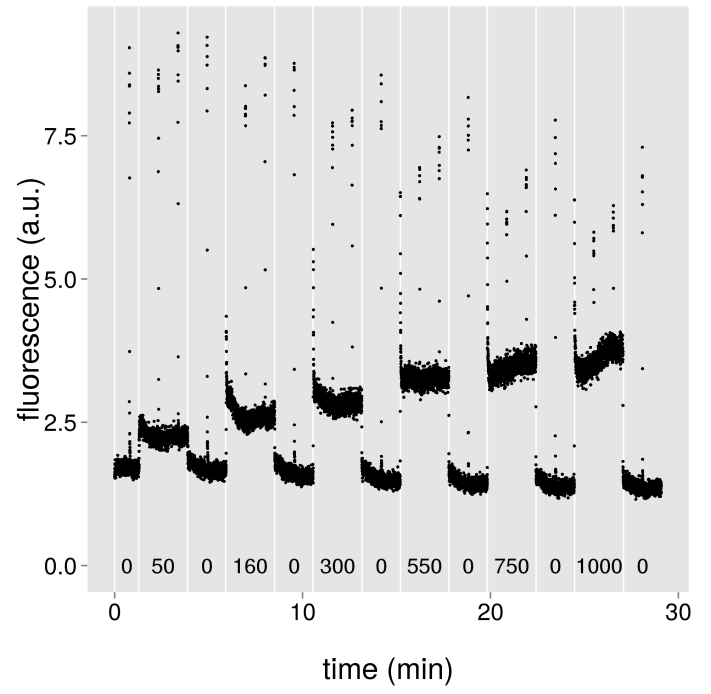

(a)

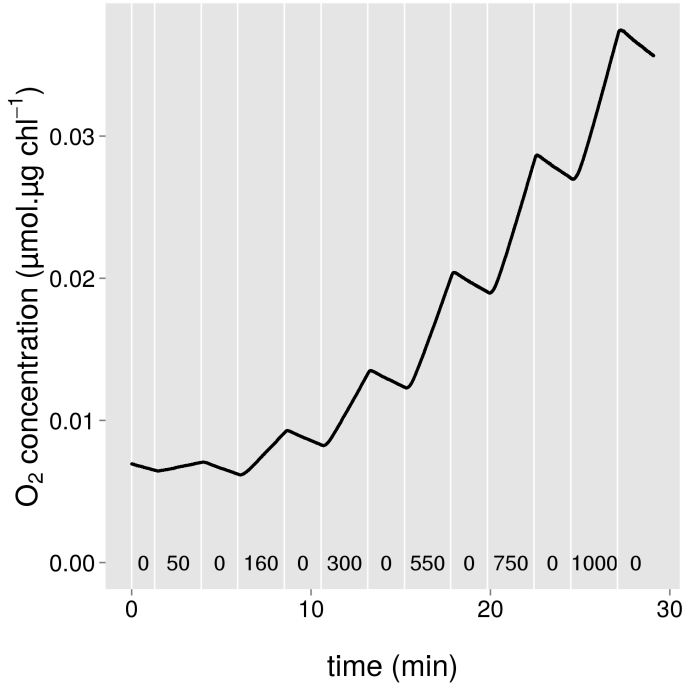

(b)

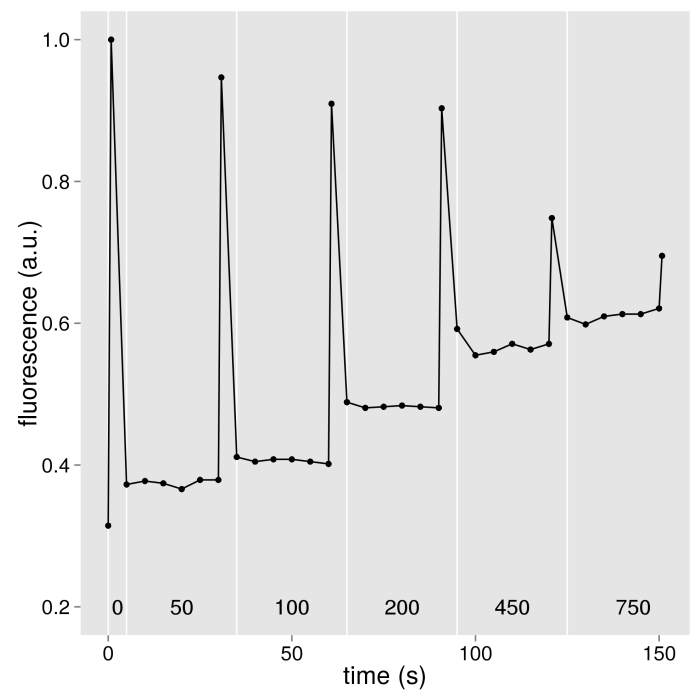

(c)

Figure S1: (a): Fluorescence trace during a typical dark-adapted experiment. (b): Variation in oxygen concentration during a typical dark-adapted experiment. Fluorescence and oxygen evolution measurements on dark-adapted samples were simultaneously recorded. (c): Fluorescence trace during a typical light-adapted experiment. Light intensities $\left(\mu \mathrm{mol}\right.$ PAR. $\left.\mathrm{m}^{-2} \cdot \mathrm{s}^{-1}\right)$ at which measurements were realised are indicated in the figure. 